\title{
Longitudinal associations of socioeconomic position in childhood and adulthood with decline in lung function over 20 years: results from a population-based cohort of British men
}

\author{
Sheena E Ramsay, ${ }^{1}$ Peter H Whincup, ${ }^{2}$ Lucy T Lennon, ${ }^{1}$ Richard W Morris, ${ }^{1}$ \\ S G Wannamethee ${ }^{1}$
}

\begin{abstract}
${ }^{1}$ Department of Primary Care and Population Health, UCL, London, UK

${ }^{2}$ Division of Population Health Sciences and Education, St George's University of London, London, UK
\end{abstract}

\section{Correspondence to} Dr Sheena E Ramsay. Department of Primary Care and Population Health, UCL Medical School, Royal Free Campus, Rowland Hill Street, London NW3 2PF, UK:

s.ramsay@ucl.ac.uk

Received 15 November 2010 Accepted 30 June 2011 Published Online First 22 July 2011

\begin{abstract}
Background Associations of socioeconomic position with lung function are reported mostly from crosssectional studies. The aim of this study was to investigate the associations between socioeconomic position both in adulthood and childhood with changes in lung function over a 20-year period.

Methods A socioeconomically representative cohort of 7735 British men aged 40-59 years was followed-up from 1978-1980 to 1998-2000. Lung function (heightstandardised forced expiratory volume in $1 \mathrm{~s}\left(\mathrm{FEV}_{1}\right)$ and forced vital capacity (FVC)) was assessed at both time points in 4252 survivors. Adult socioeconomic position was derived from longest-held occupation in middle age and childhood socioeconomic position from father's longest-held occupation.

Results Both $\mathrm{FEV}_{1}$ and FVC declined over time; the decline increased progressively from social class I (highest) to V (lowest); $p$ for trend $\leq 0.0001$. The mean difference in decline comparing manual versus non-manual groups was -0.13 litres $(95 \% \mathrm{Cl}-0.16$ to -0.10$)$ for $\mathrm{FEV}_{1}$ and -0.09 litres $(95 \% \mathrm{Cl}-0.13$ to -0.05$)$ for FVC. These differences remained after adjustment for age, cigarette smoking, body mass index, physical activity and history of bronchitis. Similar differences in lung function decline were observed comparing manual with non-manual childhood social classes, although the differences were reduced by adjustment for adult social class and risk factors. Men in manual social classes in both childhood and adulthood had the greatest decline in lung function compared to those in non-manual groups in childhood and adulthood. Conclusions Socioeconomic position across the life course could have a significant impact on decline in lung function in later life. The role of environmental factors associated with socioeconomic position merits further exploration.
\end{abstract}

\section{INTRODUCTION}

Impaired lung function is an important contributor to all-cause mortality and morbidity from cardiovascular disease, disability and type 2 diabetes. ${ }^{1-4}$ Lung function declines in later life, reflecting both age-related physiological changes in respiratory function ${ }^{5}$ and the influence of cigarette smoking, physical inactivity, weight gain and ill health. ${ }^{6-9}$ The association of lung function in adult life with

\section{Key messages}

What is the key question?

- Is lung function decline associated with socioeconomic position?

What is the bottom line?

- Lung function decline was greater in those of lower socioeconomic position; combined adverse socioeconomic position in both adult life and childhood was additionally associated with a greater decline in lung function.

Why read on?

- This study investigates the prospective association between lung function decline and socioeconomic position (both in adult life and childhood) in a representative cohort of British men.

socioeconomic position has been reported in several studies, which show that lower socioeconomic position (either in adulthood or childhood) is associated with higher levels of impaired lung function. ${ }^{6} 10-15$ Factors associated with socioeconomic position that could affect lung function include exposure to smoking, childhood respiratory infections, prenatal exposures, housing conditions, poor nutrition and air pollution. Some studies have observed the association of socioeconomic position with lung function to be independent of some of these influences, in particular cigarette smoking. ${ }^{11} 13-16$

A recent review suggests that most evidence on the relation between socioeconomic position and lung function comes from cross-sectional studies. ${ }^{10}$ Few previous studies have reported longitudinal associations of lung function with socioeconomic position. ${ }^{6} 111718$ These studies have mostly been based on younger adults ${ }^{11} 1719$ and have not reported consistent associations between decline in lung function and socioeconomic position. Moreover, no previous report to our knowledge has studied the combined effect of socioeconomic position in childhood and adult life on decline in lung function in later life. Important socioeconomic differences in mortality and morbidity are known to persist in the UK and other developed countries. ${ }^{15}{ }^{20-22}$ The contribution of socioeconomic factors to impaired lung function, which is an important determinant of 
health in later life, needs further investigation. ${ }^{23} 24$ This study, therefore, examines the association of adult and childhood socioeconomic position with decline in lung function over 20 years in British men aged $40-59$ years at baseline.

\section{METHODS}

The British Regional Heart Study is a prospective study of cardiovascular disease comprising a socially and geographically representative sample of 7735 men initially examined in 1978-1980 when aged 40-59 years, from one general practice in each of 24 towns representing all major British regions. ${ }^{25}$ Ethical approval was provided by relevant local research ethics committees. All men provided written informed consent to investigations carried out in accordance with the Declaration of Helsinki. A physical examination of participants was carried out at baseline (1978-1980) including anthropometric, spirometry and physiological measurements. Information on lifestyle factors and medical history was obtained through questionnaires. Cohort participants have been followed-up since for morbidity through two-yearly reviews of general practitioner records and for mortality through the National Health Service Central Register; contact was successfully maintained with $>98 \%$ of participants. In 1998-2000, the men, now aged 60-79, were invited to a 20-year re-assessment. At this follow-up, the subjects completed a questionnaire providing information on medical history and lifestyle factors and had a physical examination. Four thousand, two hundred and fifty-two men $(77 \%$ of surviving subjects; $80 \%$ in non-manual social classes and $70 \%$ in manual groups) attended the 20 -year follow-up examination.

\section{Socioeconomic position}

Adult socioeconomic position was based on occupational social class. This was derived from the longest-held occupation of subjects recorded at study entry (aged 40-59 years) in the baseline questionnaire (1978-1980) and classified using the Registrar General's classification of occupations-I (professionals, eg, physicians, engineers), II (managerial, eg, teachers, sales managers), III non-manual (semiskilled non-manual, eg, clerks, shop assistants), III manual (semiskilled manual, eg, bricklayers), IV (partly skilled, eg, postmen) and V (unskilled, eg, porters, general labourers). ${ }^{26}$ Subjects were also categorised into non-manual (I, II, IIInon-manual) and manual (IIImanual, IV, V) groups. Information on social class was unavailable for 15 subjects. Men with the longest-held occupation in the Armed Forces were excluded from the analyses (231 at baseline (3\%)).

In a follow-up questionnaire in 1992, subjects were asked about their father's job for the longest period of his (father's) life. This information was used to classify subjects into manual and nonmanual childhood social class groups. The Office of Population Censuses and Surveys Classification of Occupations (1980) social class coding manual was used for the classification. ${ }^{27} 28$ Two hundred sixty-eight $(5 \%)$ men who did not report their father's social class and $115(2 \%)$ men whose fathers' longest-held occupation was the Armed Forces were excluded from analyses.

\section{Lung function}

Forced expiratory volume in one second $\left(\mathrm{FEV}_{1}\right)$ and forced vital capacity (FVC) were measured as part of lung function tests at baseline and at 20-year follow-up examination. A Vitalograph spirometer (model J49-B2) was used at baseline examination. Two consecutive readings were made, and as per convention, the maximum of these two readings was used. At the follow-up reexamination, a Vitalograph Compact II instrument was used, which was calibrated at least twice daily using a precision syringe. The use of different instruments may affect the measure of lung function at the two points; however, the difference in lung function decline between social classes, which is the focus of this paper, is unlikely to be affected. $\mathrm{FEV}_{1}$ and FVC (in litres) were recorded for the best test, defined in accordance with American Thoracic Society recommendations. ${ }^{29}$ Cole has shown that dividing by the height squared is the most appropriate way of standardising lung function for stature. ${ }^{30} \mathrm{FEV}_{1}$ and FVC at both time points were height standardised to the average height, $1.73 \mathrm{~m}$, at baseline examination in the study. Thus, height standardised $\mathrm{FEV}_{1}$ (or FVC) $=\mathrm{FEV}_{1}$ (or FVC) multiplied by (1.73/ height $)^{2}$; height $=$ individual's own height.

\section{Statistical analysis}

Associations between social class and decline in $\mathrm{FEV}_{1}$ and FVC were assessed using multivariable linear regression. Decline in lung function was the difference between 20-year follow-up and baseline measurements of lung function. Data transcription error for $\mathrm{FEV}_{1}$ at baseline survey resulted in a slightly smaller number of observations for $\mathrm{FEV}_{1}$ compared with FVC. Mean decline in $\mathrm{FEV}_{1}$ and FVC was assessed across the different adult social classes. Mean decline in lung function was also obtained for nonmanual and manual childhood social class groups. To assess the combined effect of social class and to explore any interaction between childhood and adult social class, we categorised subjects into four subgroups according to both childhood and adult social class-both childhood and adult non-manual social class; childhood non-manual and adult manual social class; childhood manual and adult non-manual and childhood and adult manual social class. Each of these models was adjusted for potential confounders in the following order: (1) model 1=baseline age, (2) model $2=$ model 1 and baseline levels of $\mathrm{FEV}_{1}$ or FVC, (3) model $3=$ model 2 and cigarette smoking at baseline, (4) model $4=$ model 3 and body mass index (BMI), physical activity and history of bronchitis or asthma at baseline. The order of adjustment of variables was made so as to assess the individual contribution of variables known to be strongly related to lung function decline; therefore age, baseline $\mathrm{FEV}_{1}$ or FVC, and smoking were adjusted first in the model, followed by the final model with all variables. For adjustments, age and BMI were fitted as continuous variables (fitting these variables as categorical variables was explored, and their effect was found to be similar to their use as continuous variables); cigarette smoking was fitted as six groups (never smokers, ex-smokers, 1-19 cigarettes/day, 20 cigarettes/day, 21-39 cigarettes/day and 40 or more cigarettes/day), and physical activity was fitted as six groups (inactive, occasional, light, moderate, moderately vigorous and vigorous). Further supplementary adjustments were made in the final model to include: (1) additional measures of smoking including number of years smoked (based on age at initiation) and pack years ((cigarettes per day/20) xyears smoked) instead of current smoking; (2) change in BMI and change in smoking habit during the follow-up instead of baseline BMI and cigarette smoking and (3) childhood social class. Analyses were also stratified to investigate the relation between social class and lung function decline among never smokers and non-obese at baseline. Subsidiary analyses were carried out in a subgroup of subjects $(n=3546)$ with information on years in full-time education which was collected in 1996 subsequent to the baseline examination. Tests for trends were carried out fitting social class as continuous variables. A formal test of interaction between adult and childhood social class for their effect on lung function decline was carried out. Statistical analyses were performed using SAS V.9.1, SAS Institute Inc. 
Table 1 Characteristics of subjects of the British Regional Heart Study followed-up for 20 years from baseline in 1978-1980

\begin{tabular}{|c|c|c|}
\hline & $\begin{array}{l}\text { Baseline } \\
\text { examination }\end{array}$ & $\begin{array}{l}\text { 20-year } \\
\text { follow-up }\end{array}$ \\
\hline Mean age (SD) & $50(6)$ & $68(6)$ \\
\hline Mean $\mathrm{FEV}_{1}$ in litres (SD) & $3.3(0.7)$ & $2.6(0.7)$ \\
\hline Mean FVC in litres (SD) & $4.4(0.7)$ & $3.4(0.8)$ \\
\hline Mean BMI kg/m² (SD) & $25(3)$ & $27(4)$ \\
\hline \multicolumn{3}{|l|}{ Smoking status } \\
\hline Current smokers n (\%) & $2998(41 \%)$ & $509(13 \%)$ \\
\hline Ex-smokers n (\%) & $2610(36 \%)$ & $2362(58 \%)$ \\
\hline Never smokers n (\%) & $1767(24 \%)$ & $1204(30 \%)$ \\
\hline Pack years at baseline-median (IOR) & $46(3,100)$ & - \\
\hline \multicolumn{3}{|l|}{ Physical activity } \\
\hline Inactive/occasional n (\%) & $2921(40 \%)$ & $1357(34 \%)$ \\
\hline Light n (\%) & $1705(23 \%)$ & $739(19 \%)$ \\
\hline Moderate n (\%) & $1162(16 \%)$ & $569(14 \%)$ \\
\hline Moderate-vigorous n (\%) & $1087(15 \%)$ & $673(17 \%)$ \\
\hline Vigorous n (\%) & $500(7 \%)$ & $593(15 \%)$ \\
\hline History of bronchitis at baseline $n(\%)$ & $1315(18 \%)$ & - \\
\hline History of asthma at baseline $\mathrm{n}(\%)$ & $274(4 \%)$ & - \\
\hline Mean decline in $\mathrm{FEV}_{1}(\mathrm{SD})$ over 20 years & $-0.86(0.5)$ & \\
\hline Mean decline in FVC (SD) over 20 years & $-1.13(0.7)$ & \\
\hline
\end{tabular}

\section{RESULTS}

Of 4252 men studied at the 20-year follow-up, 4132 had information on social class and were eligible to be included in the analysis. Table 1 describes mean age, $\mathrm{FEV}_{1}, \mathrm{FVC}$ and BMI of the subjects at baseline and after 20 years of follow-up. During the follow-up, mean $\mathrm{FEV}_{1}$ and FVC levels had declined, along with a decline in the proportion of current smokers and those who were physically inactive.

Table 2 shows the mean declines in $\mathrm{FEV}_{1}(\mathrm{n}=4005)$ and FVC $(n=4008)$ in participants aged 60-79 years over the 20-year follow-up period for each adult social class group. Mean decline in $\mathrm{FEV}_{1}$ and $\mathrm{FVC}$ increased progressively from social class I to social class $\mathrm{V}$ ( $\mathrm{p}$ for trend $<0.0001$ ). Mean decline in $\mathrm{FEV}_{1}$ was -0.79 litres in non-manual groups compared to a decline of -0.93 litres in manual social classes after adjustment for baseline age and $\mathrm{FEV}_{1}$ levels. The mean difference in manual versus nonmanual groups ( -0.13 litres; $95 \%$ CI -0.16 to -0.10$)$ was little affected by further adjustment for baseline cigarette smoking, BMI, physical activity, history of bronchitis or asthma (adjusted mean difference in $\mathrm{FEV}_{1}$ decline -0.10 litres; 95\% CI -0.13 to $-0.07)$. Similar results were observed for decline in FVC levels in different adult social classes (table 2). Further adjustment for childhood social class resulted in little further change in mean difference in manual versus non-manual for decline in $\mathrm{FEV}_{1}$ $(-0.09 ; 95 \% \mathrm{CI}-0.12$ to -0.06$)$ and decline in FVC $(-0.07 ; 95 \%$ CI -0.12 to -0.03$)$.

Separate analyses adjusting for pack years or number of years smoked showed similar results; mean difference in decline in $\mathrm{FEV}_{1}$ for manual versus non-manual social classes when adjusted for pack years was -0.11 litres (95\% CI -0.14 to -0.08 ) and -0.09 litres (95\% CI -0.13 to -0.06 ) for decline in FVC. Additional analyses restricted to never smokers also showed a greater decline in lung function in manual compared to non-manual groups (mean difference for decline in $\mathrm{FEV}_{1}=-0.06$ litres $(95 \% \quad \mathrm{CI}-0.11$ to -0.007$)$ and for $\mathrm{FVC}=-0.10$ litres $(95 \% \mathrm{CI}-0.16$ to -0.03$)$ ). Results similar to those in table 2 were observed when adjustments were made for change in smoking habit or for change in BMI (mean difference manual vs non-manual was -0.10 litres $(95 \% \mathrm{CI}-0.13$ to -0.07 ) for $\mathrm{FEV}_{1}$ and -0.08 litres $(95 \% \mathrm{CI}-0.12$ to -0.04 ) for FVC). Restriction of analyses to subjects who were not obese at baseline also yielded similar social class differences in lung function decline.

Excluding those with incident coronary disease or diabetes over the follow-up also showed similar results (data not shown). Further adjustment for town of residence also did not materially

Table 2 Decline in FEV 1 and FVC over a 20-year follow-up in British men aged 40-59 years in 1978-1980 according to adult social class

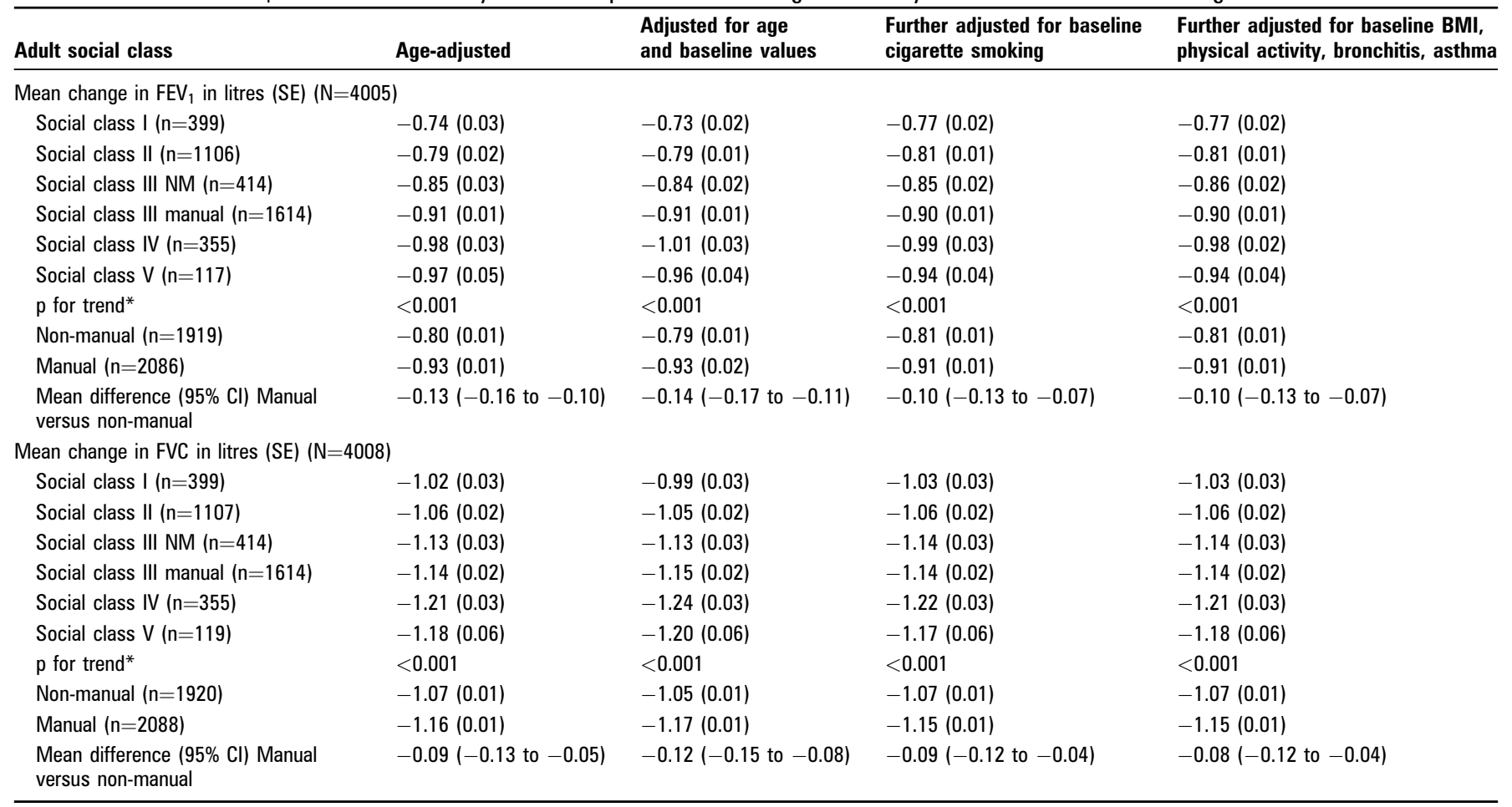

${ }^{*} \mathrm{p}$ for trend from models with social class as a continuous variable. 
Table 3 Decline in $\mathrm{FEV}_{1}$ and FVC over a 20-year follow-up in British men aged 40-59 years in 1978-1980 according to childhood social class

\begin{tabular}{|c|c|c|c|c|}
\hline Childhood social class & $\begin{array}{l}\text { Adjusted for age and } \\
\text { baseline values }\end{array}$ & $\begin{array}{l}\text { Further adjusted } \\
\text { adult social class }\end{array}$ & $\begin{array}{l}\text { Further adjusted for baseline } \\
\text { cigarette smoking }\end{array}$ & $\begin{array}{l}\text { Further adjusted for baseline } \\
\text { BMI, physical activity, } \\
\text { bronchitis, asthma }\end{array}$ \\
\hline \multicolumn{5}{|c|}{ Mean change in $\mathrm{FEV}_{1}$ in litres (SE) $(\mathrm{N}=3619)$} \\
\hline Manual $(n=2563)$ & $-0.89(0.01)$ & $-0.88(0.01)$ & $-0.88(0.01)$ & $-0.88(0.01)$ \\
\hline $\begin{array}{l}\text { Mean difference }(95 \% \mathrm{Cl}) \text { Manual } \\
\text { versus non-manual }\end{array}$ & $-0.13(-0.16$ to -0.09$)$ & $-0.08(-0.11$ to -0.04$)$ & $-0.07(-0.10$ to -0.03$)$ & $-0.07(-0.10$ to -0.03$)$ \\
\hline Non-manual $(n=1056)$ & $-1.04(0.02)$ & $-1.08(0.02)$ & $-1.08(0.02)$ & $-1.08(0.02)$ \\
\hline Manual $(n=2564)$ & $-1.14(0.01)$ & $-1.12(0.01)$ & $-1.12(0.01)$ & $-1.12(0.01)$ \\
\hline $\begin{array}{l}\text { Mean difference }(95 \% \mathrm{Cl}) \text { Manual } \\
\text { versus non-manual }\end{array}$ & $-0.09(-0.14$ to -0.05$)$ & $-0.05(-0.09$ to 0.0002$)$ & $-0.04(-0.08$ to 0.009$)$ & $-0.04(-0.08$ to 0.006$)$ \\
\hline $\mathrm{p}$ Value & $<0.001$ & 0.05 & 0.011 & 0.09 \\
\hline
\end{tabular}

change the results presented ((manual vs non-manual difference in decline in $\mathrm{FEV}_{1}=-0.09$ litres $(95 \% \mathrm{CI}-0.12$ to -0.06$)$ ). Education as a measure of socioeconomic position also yielded similar socioeconomic differences in lung function declinecompared to those in full-time education beyond the age of 14 years, subjects who were in full-time education $\leq 14$ years of age had a greater decline in lung function (mean decline in $\mathrm{FEV}_{1}=-0.10$ litres; $95 \% \mathrm{CI}-0.14$ to -0.07 ; mean decline in $\mathrm{FVC}=-0.13$ litres; $95 \% \mathrm{CI}-0.18$ to -0.08$)$. When adjusted for each other, the association of education with lung function decline was attenuated (mean decline in $\mathrm{FEV}_{1}=-0.05$ litres; $95 \%$ $\mathrm{CI}-0.09$ to -0.007 ; mean decline in $\mathrm{FVC}=-0.09$ litres; $95 \% \mathrm{CI}$ -0.14 to -0.04$)$, while that of occupational social class showed little change.

Mean decline in $\mathrm{FEV}_{1}$ and FVC over 20 years according to childhood social class are presented in table 3. Mean decline in $\mathrm{FEV}_{1}$ was greater in men of manual childhood social class compared with men of non-manual social class in childhood (mean difference in $\mathrm{FEV}_{1}$ was -0.13 litres $(95 \% \mathrm{CI}-0.16$ to $-0.09)$ and -0.09 litres for FVC (95\% CI -0.14 to -0.05$)$ ). These mean differences remained, although weakened appre- ciably, after adjustment for adult social class and other potential confounders in adult life (cigarette smoking, BMI, physical activity, history of bronchitis or asthma); the adjusted mean differences comparing manual versus non-manual childhood social class were -0.07 litres $\left(95 \% \mathrm{CI}-0.10\right.$ to -0.03 ) for $\mathrm{FEV}_{1}$ and -0.04 litres $(95 \%$ CI -0.08 to 0.006$)$ for FVC.

The combined effect of adult and childhood social class with lung function decline is presented in table 4 . Men of non-manual social classes in both adult and childhood social class (reference group) had the lowest decline in $\mathrm{FEV}_{1}$ and FVC, while those of manual groups in adulthood and childhood had the greatest declines after adjustment for confounders. Figure 1 presents the mean decline in lung function adjusted for age and baseline values according to combined childhood and adult social class. Being in manual social class either in childhood or adulthood was also associated with increased decline in lung function compared to the reference group. A test for interaction between adult and childhood social class showed no evidence that the effect of adult social class was different in those of childhood non-manual and manual groups (test for interaction, $\mathrm{p}=0.82$ for decline in $\mathrm{FEV}_{1}$, and $\mathrm{p}=0.57$ for FVC).

Table 4 Decline in $\mathrm{FEV}_{1}$ and FVC over a 20-year follow-up in British men aged 40-59 years in 1978-1980 according to combined childhood and adult social class

\begin{tabular}{|c|c|c|c|}
\hline Childhood and adult social class & $\begin{array}{l}\text { Adjusted for age } \\
\text { and baseline values }\end{array}$ & $\begin{array}{l}\text { Further adjusted for } \\
\text { cigarette smoking }\end{array}$ & $\begin{array}{l}\text { Further adjusted for baseline BMI, } \\
\text { physical activity, bronchitis, asthma }\end{array}$ \\
\hline \multicolumn{4}{|l|}{ Mean change in $\mathrm{FEV}_{1}$ in litres (SE) $(\mathrm{N}=3619)$} \\
\hline Childhood and adult - non-manual $(n=772)$ & $-0.74(0.02)$ & $-0.76(0.02)$ & $-0.76(0.02)$ \\
\hline $\begin{array}{l}\text { Childhood non-manual and adult manual } \\
\text { social class }(n=284)\end{array}$ & $-0.86(0.03)$ & $-0.85(0.03)$ & $-0.85(0.03)$ \\
\hline $\begin{array}{l}\text { Childhood manual and adult non-manual } \\
\text { social class }(n=1011)\end{array}$ & $-0.82(0.01)$ & $-0.83(0.01)$ & $-0.83(0.01)$ \\
\hline $\begin{array}{l}\text { Childhood manual and adult manual social } \\
\text { class }(n=1552)\end{array}$ & $-0.94(0.01)$ & $-0.92(0.01)$ & $-0.92(0.01)$ \\
\hline p Value* & $<0.001$ & $<0.001$ & $<0.001$ \\
\hline \multicolumn{4}{|l|}{ Mean change in FVC in litres (SE) $(N=3620)$} \\
\hline Childhood and adult - non-manual $(n=772)$ & $-1.02(0.02)$ & $-1.05(0.02)$ & $-1.04(0.02)$ \\
\hline $\begin{array}{l}\text { Childhood non-manual and adult manual } \\
\text { social class }(n=284)\end{array}$ & $-1.11(0.04)$ & $-1.10(0.04)$ & $-1.10(0.04)$ \\
\hline $\begin{array}{l}\text { Childhood manual and adult non-manual } \\
\text { social class }(n=1011)\end{array}$ & $-1.07(0.02)$ & $-1.08(0.02)$ & $-1.08(0.02)$ \\
\hline $\begin{array}{l}\text { Childhood manual and adult manual social } \\
\text { class }(n=1553)\end{array}$ & $-1.18(0.02)$ & $-1.16(0.02)$ & $-1.16(0.02)$ \\
\hline $\mathrm{p}$ Value* & $<0.001$ & $<0.001$ & $<0.001$ \\
\hline
\end{tabular}

${ }^{*} p$ Value for difference in mean decline in four groups. 
Figure 1 Mean lung function decline adjusted for age and baseline values according to combined childhood and adult social class.

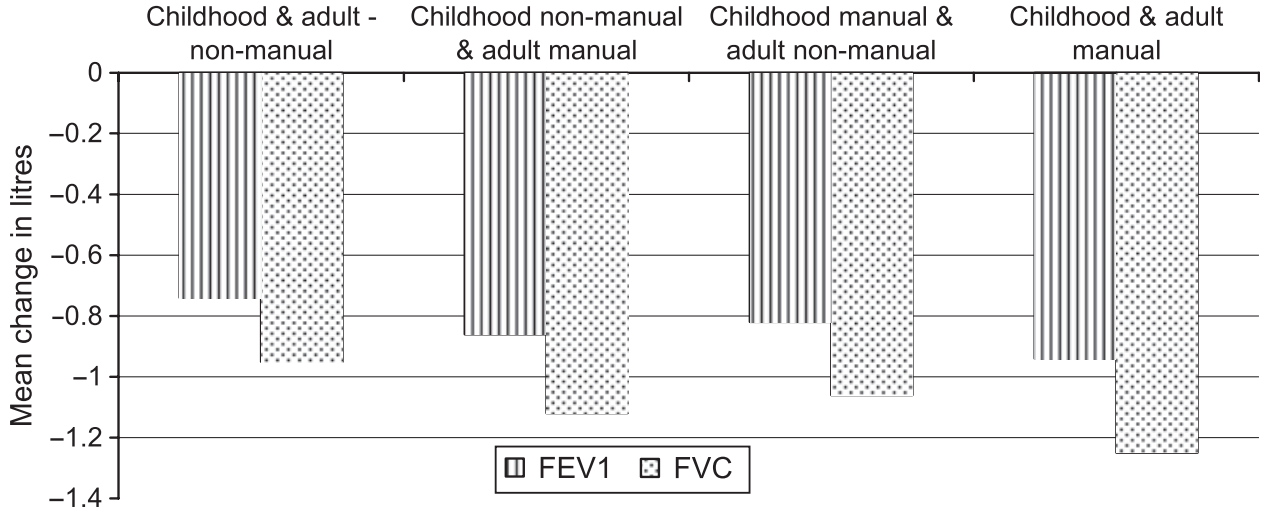

\section{DISCUSSION}

This longitudinal study in middle-aged British men shows that socioeconomic position (both in adulthood and childhood) was inversely associated with decline in lung function in later life over a 20-year follow-up period. This association, particularly for adult socioeconomic position, remained after adjustment for risk factors related to impaired lung function such as cigarette smoking and history of bronchitis and asthma. Combined adverse socioeconomic position in both adult life and childhood was additionally associated with a greater decline in lung function.

Several earlier studies have reported associations between socioeconomic position and lung function-with lower socioeconomic positions having lower levels of lung function. ${ }^{6}$ 10-15 Studies have reported separately the effects of socioeconomic position in early life $e^{11} 1431$ and in adulthood. ${ }^{6} 12 \quad 13 \quad 1518$ Consistent relations between socioeconomic position and lung function have been observed, which are also reported to be independent of important confounders such as cigarette smoking. ${ }^{11}{ }^{13-16}$ However, there are few longitudinal studies examining the relation between socioeconomic position and decline in lung function. The present study extends the findings of earlier studies by showing that the influence of socioeconomic position is related to decline in lung function with increasing age over a 20-year follow-up. This is consistent with some previous studies which examined factors associated with decline in lung function. ${ }^{611} 17-19$ Two of the earlier studies were carried out in young adults-one of the studies found adult socioeconomic position to be associated with lung function decline only in women and not in men, ${ }^{17}$ while the other study with a shorter follow-up of 5 years observed an inverse association between childhood socioeconomic position and lung function decline. ${ }^{11}$

Our study also reports the influence of socioeconomic position both in adulthood and early in life on lung function decline in later life. Although the potential for residual confounding remains, the results show that the relation of socioeconomic position, particularly in adulthood, remained even after adjustment for adult risk factors such as cigarette smoking, BMI and physical activity. Additional analyses showed that greater lung function decline in lower socioeconomic position remained in never smokers and was independent of developing chronic diseases such as myocardial infarction and diabetes or change in levels of BMI during follow-up. The adverse effect of lower childhood socioeconomic position on lung function decline in adult life persisted, although reduced to some extent by adjustment for adult risk factors and social class. These associations between socioeconomic position and lung function decline in later life could play an important role in contributing to inequalities in mortality, chronic respiratory diseases and associated disability in later life.

Particular strengths of the study are the longitudinal assessment of lung function decline in later life in a socially representative population-based sample of middle-aged British men. The measures of socioeconomic position in childhood and adult life used in the study are likely to be robust. Childhood social class, which was based on the longest-held occupation of the father, is likely to be a stable measure of childhood socioeconomic position since social mobility in the fathers of study participants was probably less marked than among men of the generation of study participants, who were more influenced by widened educational opportunities. A limitation of this measure, however, is that it was based on retrospective collection of information, raising the possibility both of random error and recall bias. A previous study showed that there maybe a tendency for socioeconomic position to be overestimated when based on recall of father's occupation. ${ }^{32}$ However, the validity of childhood social class in our study is suggested by its strong relationship with educational attainment of the subjects: a markedly lower proportion of subjects with fathers in manual occupations were educated after 18 years of age and a higher proportion left education at 14 years. The reliability of adult socioeconomic position is also important. Our measure was based on the longest-held occupation recorded at study entry in 1978-1980 when subjects were aged 40-59; this was defined for almost all study participants. The registrar general's classification of occupations was the standard UK classification of socioeconomic status at the time the study participants were in full-time occupations. Re-assessment of occupational social class was carried out 20 years later in 1998-2000; only a small proportion (8\%) changed their social class over a 20 -year period, confirming its stability as an indicator of socioeconomic position over most of adult life. Socioeconomic position in adult life can be measured using different indicators such as occupation, education and income. These indicators could be associated with health outcomes in different ways since they measure different aspects of socioeconomic position-for example, occupational social class reflects social status, education, assets, income and social circumstances, while education influences social status, material resources, informational or knowledge resources and behavioural patterns, and income or wealth captures material resources and circumstances. ${ }^{33} 34$ In our analysis on a subgroup of the cohort, the relationship of lung function decline was stronger with occupational social class than with education levels; although we were unable to undertake detailed analyses on different measures of socioeconomic position, we believe that occupational social class has important strengths as a single 
measure, taking into account aspects of education, income and status. $^{33} 34$

While contact has been maintained with more than $98 \%$ of the cohort during the follow-up, an inevitable result of our study is that the analyses were restricted to participants who survived until the 20-year follow-up. Survivors are likely to be healthier with better lung function than those who did not survive to the follow-up. However, this issue of survival bias is likely to occur in all socioeconomic groups and, therefore, is unlikely to bias the association of socioeconomic position with decline in lung function which is the key finding of this study; if anything, greater mortality in manual social classes over the follow-up ${ }^{20}$ may have underestimated the true association between social class and lung function. Nevertheless, supplementary analysis restricted to never smokers at baseline also showed associations that were similar to overall results presented. The measure of lung function at both time points of follow-up is also dependent on participants being healthy enough to perform the test. However, in our study population, lung function tests were available for almost all participants $(99 \%$ at baseline and at 20 year follow-up). Owing to lack of information, we could not explore the role of occupational exposure to harmful airborne agents. However, airborne factors are unlikely to explain the association between socioeconomic position and lung function for two reasons-first, the graded association between socioeconomic position and lung function was observed even within non-manual social classes, with a marked decline in social class IIInon-manual (semiskilled occupations such as clerks) compared with social class I (professionals). Second, adjustment for town of residence (strongly related to air pollution levels) had little or no effect. Nevertheless, the role of occupational exposure merits further research, and this is a limitation of our study. Finally, since this study comprised white European men, the results may not be directly generalisable to women and to other ethnic groups, though the results of previous studies, which have found socioeconomic position to be associated with lung function in women and in other ethnic groups, ${ }^{12} 1535$ suggest that our findings may have wider applicability.

\section{Implications and conclusions}

The findings of our study imply that socioeconomic position influences decline in lung function in later life and that this may be independent of risk factors such as cigarette smoking, BMI, physical activity and co-morbidities. The particular additive influence of socioeconomic position in early life and adulthood on decline in lung function was also observed. Given that lung function is a strong predictor of mortality and morbidity in later life, the role of socioeconomic position on health in later life is likely to be important. The exact mechanisms underlying the associations between socioeconomic position and decline in lung function merits further research. Likely contributors to this association are poor diet, environmental factors such as air pollution, housing environment and occupational exposures; some of these factors could be operating from early in life in addition to maternal undernutrition and low birth weight. ${ }^{10} 3136$ The findings of this study highlight the need to understand and improve socioeconomic conditions associated with lower socioeconomic position across the life course, which is likely to improve an important health outcome such as impaired lung function.

Funding The British Regional Heart Study is a British Heart Foundation Research Group. The views expressed in this publication are those of the authors and not necessarily those of the funding body.
Ethics approval This study was conducted with the approval of Multicentre Research Ethics Committee.

Contributors SER, PHW, RWM, SGW developed the original idea for the paper, and SER wrote the first draft. SER performed the analyses. PHW, LTL, RWM and SGW contributed to the design and execution of the British Regional Heart Study. All authors contributed to interpretation of data and the final version of the manuscript, and all are guarantors.

Provenance and peer review Not commissioned; externally peer reviewed.

\section{REFERENCES}

1. Eisner MD, Iribarren $\mathrm{C}$, Yelin $\mathrm{EH}$, et al. Pulmonary function and the risk of functional limitation in chronic obstructive pulmonary disease. Am J Epidemiol 2008:167:1090-101.

2. Schroeder EB, Welch VL, Couper D, et al. Lung function and incident coronary heart disease: the atherosclerosis risk in communities study. Am J Epidemiol 2003;158:1171-81.

3. Schunemann HJ, Dorn J, Grant BJ, et al. Pulmonary function is a long-term predictor of mortality in the general population: 29-year follow-up of the Buffalo Health Study. Chest 2000;118:656-64.

4. Wannamethee SG, Shaper AG, Rumley A, et al. Lung function and risk of type 2 diabetes and fatal and non-fatal major coronary heart disease events: possible associations with inflammation. Diabetes Care 2010;33:1990-6.

5. Janssens JP, Pache JC, Nicod LP. Physiological changes in respiratory function associated with ageing. Eur Respir J 1999;13:197-205.

6. Burchfiel CM, Marcus EB, Sharp DS, et al. Characteristics associated with rapid decline in forced expiratory volume. Ann Epidemiol 1996;6:217-27.

7. Griffith K, Sherrill D, Siegel E, et al. Predictors of loss of lung function in the elderly. The Cardiovascular Health Study. Am J Respir Crit Care Med 2001;163:61-8.

8. Pelkonen M, Notkola IL, Lakka T, et al. Delaying decline in pulmonary function with physical activity: a 25-year follow-up. Am J Respir Crit Care Med 2003;168:494-9.

9. Wise RA, Enright PL, Connett JE, et al. Effect of weight gain on pulmonary function after smoking cessation in the Lung Health Study. Am J Respir Crit Care Med 1998;157:866-72.

10. Hegewald MJ, Crapo RO. Socioeconomic status and lung function. Chest 2007;132:1608-14

11. Jackson B, Kubzansky LD, Cohen $S$, et al. A matter of life and breath: childhood socioeconomic status is related to young adult pulmonary function in the CARDIA study. Int J Epidemiol 2004;33:271-8.

12. Prescott $\mathbf{E}$, Lange $P$, Vestbo J. Socioeconomic status, lung function and admission to hospital for COPD: results from the Copenhagen City Heart Study. Eur Respir J 1999; 13:1109-14.

13. Wheeler BW, Ben-Shlomo Y. Environmental equity, air quality, socioeconomic status, and respiratory health: a linkage analysis of routine data from the Health Survey for England. J Epidemiol Community Health 2005;59:948-54.

14. Lawlor DA, Ebrahim S, Davey SG. Association between self-reported childhood socioeconomic position and adult lung function: findings from the British Women's Heart and Health Study. Thorax 2004;59:199-203.

15. Eisner MD, Blanc PD, Omachi TA, et al. Socioeconomic status, race and COPD health outcomes. J Epidemiol Community Health 2011;65:26-34.

16. Prescott $\mathbf{E}$, Vestbo J. Socioeconomic status and chronic obstructive pulmonary disease. Thorax 1999;54:737-41.

17. Tabak C, Spijkerman AMW, Verschuren WMM, et al. Does educational level influence lung function decline (Doetinchem Cohort Study)? Eur Respir J 2009;34:940-7.

18. Johannessen A, Eagen T, Omenaas E, et al. Socioeconomic risk factors for lung function decline in a general population. Eur Respir J 2010;36:480-7.

19. Sunyer J, Zock JP, Kromhout H, et al: for the Occupational Group of the European Community Respiratory Health Survey. Lung function decline, chronic bronchitis, and occupational exposures in young adults. Am J Respir Crit Care Med 2005; 172:1139-45

20. Ramsay SE, Morris RW, Whincup PH, et al. Are social inequalities in mortality in Britain narrowing? Time trends from 1978 to 2005 in a population-based study of older men. J Epidemiol Community Health 2008;62:75-80.

21. Huisman $\mathbf{M}$, Kunst $A E$, Bopp $\mathbf{M}$, et al. Educational inequalities in cause-specific mortality in middle-aged and older men and women in eight western European populations. Lancet 2005;365:493-500.

22. Kunst AE, Groenhof F, Andersen 0, et al. Occupational class and ischemic heart disease mortality in the United States and 11 European countries. Am J Public Health 1999:89:47-53.

23. Guerra S, Sherrill DL, Venker C, et al. Morbidity and mortality associated with the restrictive spirometric pattern: a longitudinal study. Thorax 2010;65 499-504.

24. Mannino DM, Davis KJ. Lung function decline and outcomes in an elderly population. Thorax 2006;61:472-7.

25. Walker M, Whincup PH, Shaper AG. The British Regional Heart Study 1975-2004 Int J Epidemiol 2004;33:1185-92.

26. Classification of Occupations 1970. London: HM Stationary Office, 1970.

27. Office of Population Censuses and Surveys. Classification of occupations and coding index. London: HM Stationery Office, 1980. 
28. Wannamethee SG, Whincup PH, Shaper G, et al. Influence of fathers' social class on cardiovascular disease in middle-aged men. Lancet 1996;348:1259-63.

29. American Thoracic Society. Standardization of spirometry: 1994 update. Am J Respir Crit Care Med 1995;152:1107-36.

30. Cole TJ. Linear and proportional regression models in the prediction of ventilatory function: with discussion. J R Stat Soc Ser A 1975;138:297-338.

31. Orfei L, Strachan DP, Rudnicka AR, et al. Early influences on adult lung function in two national British cohorts. Arch Dis Child 2008;93:570-4.

32. Batty GD, Lawlor DA, Macintyre S, et al. Accuracy of adults' recall of childhood social class: findings from the Aberdeen children of the 1950s study. J Epidemiol Community Health 2005;59:898-903.
33. Galobardes B, Shaw M, Lawlor DA, et al. Indicators of socioeconomic position (part 1). J Epidemiol Community Health 2006;60:7-12.

34. Krieger N, Williams DR, Moss NE. Measuring social class in US public health research: concepts, methodologies, and guidelines. Annu Rev Public Health 1997; 18:341-78

35. Harik-Khan R, Fleg J, Muller DC, et al. The effect of anthropometric and socioeconomic factors on the racial difference in lung function. Am J Respir Crit Care Med 2001;164:1647-54.

36. Lawlor DA, Ebrahim S, Davey SG. Association of birth weight with adult lung function: findings from the British Women's Heart and Health Study and a metaanalysis. Thorax 2005;60:851-8.

\section{Journal club}

\section{Palliative care in severe COPD: how and when?}

Palliative care in chronic obstructive pulmonary disease (COPD) is an area that needs development. Existing palliative care models for cancer and chronic diseases such as heart failure do not seem to fit well with problems encountered by patients with COPD. This study obtained qualitative data about living and dying with COPD from serial interviews with 21 patients with end-stage COPD, and their informal and professional careers. The data were coded, themes drawn out and the 'story' of their COPD delineated.

The near-universal pattern was an illness with no clear start, reflecting the insidious onset. COPD became 'a way of life' in the middle, ruled by unpredictable exacerbations and no clear trajectory of illness progression. Patients were symptomatic but described themselves as 'well' between exacerbations, adapting to their breathlessness and accepting it as a natural part of ageing. At the end of the story, death was unpredictable, and patients' expectations of dying were similar to that of people with no chronic illness. Professional carers' narratives often reflected those of their patients, with particular difficulty establishing a likely prognosis and appropriate point of transition to palliative care, influenced by longstanding relationships and established patterns of consultations which were hard to change.

Overall, this study demonstrated that disease progression in COPD can be described as a 'chaos narrative' unlike that of other life-limiting illnesses which have a better defined trajectory. The authors proposed a system of integrated palliative and supportive care assessments throughout the patient journey, prompted by milestones such as hospital admission and starting long-term oxygen therapy, with specialist input for the management of intractable symptoms.

Pinnock H, Kendall M, Murray SA, et al. Living and dying with severe chronic obstructive pulmonary disease: multi-perspective longitudinal qualitative study. BMJ 2011;342:d142. doi:10.1136/bmj.d142.

\section{Anna Moore}

Correspondence to Anna Moore, ST3 in respiratory medicine, Southend University Hospital NHS Foundation Trust, Prittlewell Chase, Westcliff-on-Sea, Essex SS0 ORY, UK; annamoore83@yahoo.co.uk

Published Online First 31 March 2011

Thorax 2011;66:1064. doi:10.1136/thoraxjnl-2011-200115 